Adriana do Lago Alves Costa ${ }^{1}$

Ana Maria Fernandes Pitta ${ }^{2}$

Edith Maria Barbosa Ramos ${ }^{1}$

\title{
INVESTIGAÇÃO SOB A ÓTICA DA JUDICIALIZAÇÃO DA SAÚDE SOBRE UNIDADE DE TERAPIA INTENSIVA NO MUNICÍPIO DE SÃO LUÍS/MA
}

Investigation under the viewpoint of health judicialization of an intensive therapy unit in the city of São Luís, State of Maranhão, Brazil

${ }^{1}$ Universidade Ceuma. São Luís/MA, Brasil.

${ }^{2}$ Universidade Católica de Salvador. Salvador/BA, Brasil.

Correspondência: Adriana do Lago Alves Costa. E-mail: adrilagosluis@gmail.com

Recebido: 12/09/2017. Revisado: 11/12/2017. Segunda revisão: 19/04/2018. Terceira revisão: 20/07/2018. Aprovado: 12/11/2018. 


\section{RESUMO}

Estudo acerca da judicialização da saúde na concessão de leitos de unidade de terapia intensiva adulto, por meio do Poder Judiciário no Maranhão. Objetivou compreender o fenômeno da judicialização a partir das características das demandas judiciais quanto a requerente, requerido e processo, compreendendo os critérios dos juízes em suas decisões e verificando o cumprimento das sentenças, devido ao aumento expressivo do número de processos judiciais com pedido de leito de unidade de terapia intensiva adulta em São Luís, Maranhão. Trata-se de estudo documental, em que foram selecionados 25 processos judiciais transitados em julgado, com pedido de unidade de terapia intensiva, entre janeiro de 2009 a fevereiro de 2016 . Os resultados demonstraram que ações individuais com pedido de unidade de terapia intensiva adulto corresponderam a 25 (100\%); com representação por advogado particular, $15(60 \%)$; oriundos do serviço público de saúde, 16 (64\%); do gênero masculino, 14 (56\%); e prevaleceram idosos, na faixa etária entre 80-99 anos de idade, em 11 (44\%) dos processos selecionados e analisados. A maioria dos juízes utilizou a Constituição Federal de 1988, notadamente o direito à saúde, como critério na tomada de decisão. Cabe ressaltar que, no cumprimento das decisões, um número maior de pacientes teve acesso à unidade de terapia intensiva. Diante da premente necessidade de diálogo entre os poderes Executivo e Judiciário para tornar mais célere o atendimento das demandas, cresce a importância do instituto da mediação sanitária como alternativa mais rápida e eficaz na negociação entre os sistemas de saúde público e particular e o Judiciário maranhense, na busca da garantia constitucional do direito à saúde para todos.

\section{Palavras-Chave:}

Direito à Saúde; Judicialização da Saúde; Judiciário Maranhense; Unidade de Terapia Intensiva.

\section{ABSTRACT}

Study on the judicialization of health relative to the granting of beds of adult intensive care units, through the Judicial Power in the Brazilian state of Maranhão. The objective of this study is to understand the phenomenon of judicialization, based on the characteristics of the lawsuits in relation to claimant, defendant and process, understanding the judges' criteria for their decisions and verifying compliance with these decisions, due to the significant increase in the number of lawsuits originated by the demand of beds in adult intensive care units in São Luís, capital of the state of Maranhão. It is a documentary study, with a selection of 25 legal cases with final judgments, containing an intensive care unit request, occurred between January 2009 and February 2016. The results showed that individual actions with an adult intensive care unit demand corresponded to $25(100 \%)$; actions with the representation of a private lawyer 15 (60\%); from the public health service $16(64 \%)$; male gender 14 (56\%); and elderly people in the age range between $80-99$ years 11 (44\%) being these the prevailing processes among those selected and analyzed. The majority of judges used the Brazilian Federal Constitution of 1988 markedly the right to health, as the criterion for decision-making. It should be noted that, in compliance with the decisions, a greater number of patients had access to intensive care units. In view of the urgent need for dialogue between the Executive and Judicial powers, to expedite the fulfillment of demands, the importance of the sanitary mediation institute is increasing as a faster and more effective alternative of negotiation between public and private health systems and the Judicial Power of Maranhão, in the pursue of the constitutional guarantee of the right to health for all.

\section{Keywords:}

Right to Health; Judicialization of Health; Judicial Power of Maranhão; Intensive Care Units. 


\section{Introdução}

O direito à saúde é uma primazia no arcabouço dos direitos fundamentais, pois decorre do direito à vida, necessitando de um tratamento especial pelo poder público para sua concretização. Assim, pode-se afirmar que é um direito público subjetivo tutelado constitucionalmente, devendo o poder público formular políticas públicas sociais e econômicas que visem à garantia do direito de acesso universal e igualitário aos serviços de saúde. Está previsto na Constituição do Estado do Maranhão de 1989, artigo 206: "Como integrante do Sistema Único de Saúde, cabe ao Estado a organização e a defesa da saúde pública, por meio de medidas preventivas e da prestação dos serviços necessários"1.

Com base no artigo 196 da Constituição Federal de 1988 (CF/88) que determina "a saúde é um direito de todos e um dever do Estado"2, o número de pessoas que recorrem à Justiça para assegurar tal direito tem crescido consideravelmente ${ }^{3}$. A judicialização do direito à saúde consiste em buscar o Poder Judiciário como alternativa para a garantia de acesso a medicamentos ou a tratamento no Sistema Único de Saúde (SUS) ou, ainda, no sistema privado de saúde.

O Sistema Único de Saúde (SUS) é um grande projeto, um grande passo para a concretização da saúde no país, respeitando o princípio da cidadania, cujo objetivo é de estender o serviço ao maior número de pessoas possíveis (sic), garantindo um serviço adequado e de qualidade que atenda às necessidades da população sem qualquer distinção. No entanto, a realidade é bem diferente, já que o sistema apresenta vários problemas de organização e principalmente de gestão ${ }^{4}$ (Portaria n. 1.631/2015).

Com o crescimento das demandas judiciais, o orçamento voltado para ações e programas de atendimento coletivo das populações tem aumentado exponencialmente os gastos para o cumprimento das decisões judiciais ${ }^{5}$. As despesas do Ministério da Saúde para cumprir decisões judiciais de compra de medicamentos e

\footnotetext{
${ }^{1}$ MARANHÃO. Constituição do Estado do Maranhão. São Luís-MA: Imprensa: Oficial, 1989. Disponível em: http://www2.senado.leg.br/bdsf/handle/id/70443. Acesso em: 25 set. 2016.

${ }^{22}$ BRASIL. Constituição da República Federativa do Brasil de 1988. Disponível em: http://www.planalto.gov. br/ccivil_03/constituicao/constituicaocompilado.htm. Acesso em: 11 dez. 2019.

${ }^{3}$ GOMES, Vanessa Santana; AMADOR, Tania Alves. Estudos publicados em periódicos indexados sobre decisões judiciais para acesso a medicamentos no Brasil: uma revisão sistemática. Cad. Saúde Pública, Rio de Janeiro, v. 31, n. 3, p. 451-462, mar. 2015. Disponível em: http://www.scielo.br/scielo.php?script=sci_arttext\&pid=S0102311X2015000300451\&lng=en\&nrm=iso. http://dx.doi.org/10.1590/0102-311x00219113.

${ }^{4}$ CALLIARI, Gabriela; TEIXEIRA, Alessandra Vanessa. A judicialização da saúde e a má distribuição de recursos para medicamentos de baixa escala e/ou alto custo. Revista Eletrônica Direito e Política, v. 12, n. 1, p. 202-220, 2017. Disponível em: https://siaiap32.univali.br/seer/index.php/rdp/article/view/10407/0. Acesso em: 13 mar. 2018.

${ }^{5}$ MINISTÉRIO DA SAÚDE. Portaria n. 1.631, de 1 de outubro de 2015. Aprova critérios e parâmetros para o planejamento e programação de ações e serviços de saúde no âmbito do SUS. Disponível em: http://bvsms. saude.gov.br/bvs/saudelegis/gm/2015/prt1631_01_10_2015.html. Acesso em: 03 jan. 2017.
} 
insumos para tratamentos médicos aumentaram $1.300 \%$ em sete anos, saindo de $\mathrm{R} \$$ 70 milhões em 2008 para R\$ 1 bilhão em 2015, de acordo com conclusões de uma auditoria do Tribunal de Contas da União (TCU) ${ }^{6}$ que apresentou um panorama da judicialização da saúde no país.

De acordo com Gomes e Amador,

Em função da crescente demanda, estudos têm sido conduzidos, em diferentes estados brasileiros, na tentativa de entender o fenômeno da judicialização, traçando o perfil dos processos, fazendo inferências sobre as causas, caracterizando os diversos aspectos envolvidos e apontando alternativas que possam solucionar os problemas ${ }^{7}$.

Houve um crescimento no número de publicações a respeito da judicialização da saúde no Brasil e em diferentes partes do mundo, uma vez que ela vem acarretando importantes impactos nas políticas públicas e nos orçamentos, principalmente dos países cuja economia ainda está em desenvolvimento ${ }^{8}$. Essa expressividade deve-se, principalmente, à expansão do debate democrático acerca dos direitos humanos e ao novo constitucionalismo?.

A discussão sobre o acesso às ações e serviços de saúde pela via judicial no Brasil ganhou importância teórica e prática, envolvendo crescentes debates entre acadêmicos, operadores do direito, gestores públicos, profissionais da saúde e sociedade civil, trazendo para o centro da discussão a atuação do Poder Judiciário em relação à garantia do direito à saúde ${ }^{10}$.

Desse modo, a concretização de tais políticas em contraponto à dificuldade orçamentária tem gerado uma série de precariedades assistenciais e insuficiência de serviços, como os de alta complexidade, especialmente no que diz respeito a Unidades de Terapia Intensiva (UTI). Esta pesquisa motiva-se pela realidade experimentada por diversos profissionais, pacientes e toda a sociedade na constante

\footnotetext{
${ }^{6}$ FABRINI, Fábio; FORMENTI, Lígia; FELIX, Paula. Despesa “judicial” no Ministério da Saúde avança 1.300\% em 7 anos. Revista Exame, São Paulo, p. 1-5, ago. 2017. Disponível em: http://exame.abril.com.br/brasil/ despesa-judicial-no-ministerio-da-saude-avanca-1-300-em-7-anos/. Acesso em: 23 out. 2017.

${ }^{7}$ GOMES, Vanessa Santana; AMADOR, Tania Alves. op. cit., p. 452.

${ }^{8}$ YEPES, Rodrigo Uprimny. A judicialização da política na Colômbia: casos, potencialidades e riscos. Sur, rev. int. direitos human., São Paulo, v. 4, n. 6, p. 52-69, 2007. Disponível em: http://www.scielo.br/scielo. php?script=sci_arttext\&pid=S1806-64452007000100004\&lng=en\&nrm=iso. http://dx.doi.org/10.1590/ S1806-64452007000100004.

${ }^{9}$ DALLARI, Sueli Gandolfi. Aspectos particulares da chamada judicialização da saúde. Revista de Direito Sanitário, São Paulo, v. 14, n. 1, p. 77, mar./jun. 2013. Disponível em: http://www.revistas.usp.br/rdisan/ article/view/56624/59641. https://doi.org/10.11606/issn.2316-9044.v14i1p77-81.

${ }^{10}$ BLIACHERIENE, Ana Carla; SANTOS, José Sebastião dos; RUBIM, Thiago Freitas. Delimitação do sentido normativo dos princípios doutrinários do direito à saúde como parâmetro mitigador da judicialização das políticas públicas de saúde. Revista Eletrônica Jurídica, v. 3, n. 2, p. 76, 2016. Disponível em: http://www. periodicosibepes.org.br/index.php/redir/article/view/2402. Acesso em: 02 abr. 2018.
} 
busca por assistência de qualidade e por acesso à rede pública de saúde no Estado do Maranhão. Também é motivada pelo crescente número de ações ajuizadas solicitando UTI ${ }^{11}$ com o intuito de socorrer o direito à saúde, que é consagrado na CF/88.

A relevância desta pesquisa repousa na efetivação do direito fundamental à saúde pelo acesso e concessão de leitos de UTI em São Luís, Maranhão, por meio do Poder Judiciário. Conforme dados coletados e informações disponibilizadas, pretendeu-se responder ao seguinte questionamento: quais são as características e o desfecho final das ações judicias sobre leitos de UTI em São Luís?

Dessa forma, pretendeu-se compreender a judicialização da saúde na concessão de leitos de UTI adulto na cidade de São Luís, visto que o campo jurídico é uma realidade palpável, encontrada para o pleno exercício do direito fundamental à vida. É necessário elucidar o que efetivamente tem sido feito para mudar a realidade, tendo em vista que a saúde é um dos preceitos básicos para a qualidade de vida humana, de modo que nenhum esforço para torná-la acessível pode ser desperdiçado.

\section{Metodologia}

Trata-se de pesquisa documental, na qual foram selecionados 25 processos transitados em julgado, com pedidos de UTI adulto entre janeiro de 2009 e fevereiro de 2016. O período de estudo foi escolhido devido tanto ao momento histórico, jurídico e social que o país tem vivenciado nos últimos sete anos quanto ao longo período de tramitação dos processos. A unidade de análise do estudo foram processos judiciais transitados em julgado e com sentenças (já resolvidos pelo Judiciário), referentes a ações de pacientes contra o ente estatal (estado ou município). A pesquisa foi realizada em duas varas da fazenda pública, escolhidas por conveniência, no Fórum Desembargador Sarney Costa, localizado na cidade de São Luís, Estado do Maranhão. A coleta de dados foi realizada no período de setembro a novembro de 2016, com auxílio de questionário, com perguntas semiestruturadas subdivididas entre abertas e fechadas, e com o apoio de servidores públicos para localização dos processos. Os processos foram escolhidos aleatoriamente, assim como acontece na distribuição do fórum, pois não havia um sistema de banco de dados no momento da pesquisa.

O projeto de pesquisa foi submetido à Plataforma Brasil e ao Comitê de Ética em Pesquisa da Universidade Ceuma, obtendo aprovação CAAE n. 57888216.3.0000.5084.

\footnotetext{
${ }^{11}$ WANG, Daniel Wei L.; VASCONCELOS, Natália Pires de; OLIVEIRA, Vanessa Elias de; TERRAZAS, Fernanda Vargas. Os impactos da judicialização da saúde no município de são paulo: gasto público e organização federativa. Rev. Adm. Pública, Rio de Janeiro, v. 48, n. 5, p. 1191-1206, out. 2014. Disponível em: http:// www.scielo.br/pdf/rap/v48n5/06.pdf. http://dx.doi.org/10.1590/0034-76121666.
} 


\section{Judicialização da saúde}

A judicialização da saúde é um tema abrangente e atual, que trata da realidade das políticas públicas na área da saúde. Trata-se da intervenção do Judiciário em tais políticas públicas, quando pacientes demandam a garantia de acesso a tratamentos e assistência em saúde. Ocorre que existem diversos entendimentos acerca do assunto e, em muitos casos, essa falta de sintonia dificulta a resolução de conflitos, que em determinado momento necessitam de uma resposta rápida.

Assim, a magnitude da discussão implica impactos significativos na organização do sistema de saúde. Esses impactos exigem maior atenção, por meio de informações e conceitos que diminuam as diferenças de comportamento sobre a temática entre os poderes.

Corroborando para concretização dessa discussão, convém destacar alguns pensamentos. Para contextualização:

O termo "judicialização da saúde" tem sido objeto de amplo debate acadêmico e a temática gera discussões em várias áreas do conhecimento, com contribuições em especial de juristas, profissionais da saúde, gestores públicos, pela diversidade de atores envolvidos ${ }^{12}$.

Mas o que seria judicialização? Para Luís Roberto Barroso, "Judicialização significa que algumas questões de larga repercussão política ou social estão sendo decididas por órgãos do Poder Judiciário, e não pelas instâncias políticas tradicionais: o Congresso Nacional e o Poder Executivo [...]"13.(Destaque nosso). Judicializar significa tratar judicialmente, chegar a um julgamento ou decisão.

Tendo em vista o cenário que se apresenta:

No Brasil, a judicialização da saúde tem sido objeto de debate, não só no que se refere às alternativas de processos, de tomada de decisão sobre a alocação orçamentária, especialmente no que se refere à insuficiência, dos recursos atualmente alocados, como também sobre a desorganização do Estado na definição e implementação das políticas relacionadas ao tema ${ }^{14}$.

\footnotetext{
${ }^{12}$ MACHADO, Teresa Robichez. Judicialização da saúde e contribuições da teoria de justiça de Norman Daniels. Revista de Direito Sanitário, São Paulo, v. 16, n. 2, p. 54, jul./out. 2015. Disponível em: http:// www.revistas.usp.br/rdisan/article/view/106891/105511. https://doi.org/10.11606/issn.2316-9044. v16i2p52-76.

${ }^{13}$ BARROSO, Luís Roberto. Judicialização, ativismo judicial e legitimidade democrática. Anuário lberoamericano de Justiça Constitucional, n. 13, p. 17-32, 2009. Disponível em: https://www.e-publicacoes.uerj.br/index. php/synthesis/article/download/7433/5388. Acesso em: 21 dez. 2016.

${ }^{14}$ MACHADO, Teresa Robichez. op. cit., p. 60.
} 
Nessa assertiva, é pertinente destacar também que "o Brasil experimenta um quadro original no cenário internacional da última década de judicialização da política de saúde, em países com sistemas universais públicos - aqui, o bem protegido é o direito à saúde" 15 . A CF/88 reconheceu o direito à saúde como um direito social em seu artigo $6^{\circ}$; definiu competências normativas e materiais para a atuação da União, dos estados e dos municípios em matéria da saúde (arts. 23, II; 24, XII; e 30, VII); e tratou da criação do SUS, de seus princípios orientadores fundamentais e dos direitos básicos do cidadão em relação ao sistema, além da organização e o funcionamento dos serviços de saúde no Brasil ${ }^{16}$.

A integralidade dos serviços públicos de saúde, com prioridade para as ações preventivas, abarca a noção de que o sistema público deve oferecer atenção integral às pessoas, compreendendo ações de promoção, prevenção e recuperação da saúde e englobando serviços de atenção primária, secundária e terciária. Isso implica que, sempre que houver uma pessoa doente, caberá ao Estado fornecer o tratamento terapêutico para a recuperação da saúde dessa pessoa, de acordo com as possibilidades oferecidas pelo desenvolvimento científico e tecnológico, não importando o nível de complexidade exigido ${ }^{17}$.

Diante das mudanças que se apresentam no Brasil, na questão da saúde há uma preocupação conjunta dos poderes e começam a surgir alternativas de adaptação à realidade jurídica sob a égide da lei.

Corroborando esse entendimento, Izamara Damasceno Cantanhede Torres escreve que:

Por tudo isso, a judicialização da saúde tornou-se uma preocupação nacional, chegando a motivar a realização de uma Audiência Pública no Supremo Tribunal Federal. Após a realização dessa Audiência, a Recomendação $n^{\circ} 31 / 2010$ do Conselho Nacional de Justiça determinou que cada Estado estabelecesse um Comitê Executivo, compondo o Fórum Nacional da Saúde para o monitoramento e a solução de demandas judiciais relativas à assistência à saúde ${ }^{18}$.

\footnotetext{
${ }^{15}$ DINIZ, Debora; MACHADO, Teresa Robichez de Carvalho; PENALVA, Janaina. A judicialização da saúde no Distrito Federal, Brasil. Ciênc. saúde coletiva, Rio de Janeiro, v. 19, n. 2, p. 591-598, fev. 2014. Disponível em: http://www.scielo.br/scielo.php?script=sci_arttext\&pid=S1413-81232014000200591\& Ing=en\&nrm=iso. Acesso em: 03 jan. 2017. http://dx.doi.org/10.1590/1413-81232014192.23072012. Acesso em: 3 jan. 2017.

${ }^{16}$ BLIACHERIENE, Ana Carla; SANTOS, José Sebastião dos; RUBIM, Thiago Freitas. op. cit., p. 76.

${ }^{17}$ AITH, Fernando Mussa Abujamra; BUJDOSO, Yasmin; NASCIMENTO, Paulo Roberto do; DALLARI, Sueli Gandolfi. Os princípios da universalidade e integralidade do SUS sob a perspectiva da política de doenças raras e da incorporação tecnológica. Revista de Direito Sanitário, São Paulo, v.15, n.1, p. 13, mar./jun. 2014. Disponível em: http://www.revistas.usp.br/rdisan/article/viewFile/82804/85759. Acesso em: 10 abr. 2018. https://doi.org/10.11606/issn.2316-9044.v15i1p10-39.

${ }^{18}$ TORRES, Izamara Damasceno Catanheide. Judicialização do acesso a medicamentos no Brasil: uma revisão sistemática. Salvador: [s.n.], 2013. p. 11.
} 
Assim, com a elaboração de resoluções e recomendações no intuito de implementar ações que visam a melhorar o trabalho no judiciário, tem-se que:

A Resolução n. 107/2010 instituiu o Fórum do Judiciário para a Saúde; a Recomendação n. 31/2010 prevê uma série de orientações aos Tribunais, magistrados e escolas de formação de juízes; a Recomendação n. 36/2011 estabelece orientações destinadas a assegurar maior eficiência na solução das demandas judiciais; e a Recomendação n. 43/2013, recomenda a especialização das varas para processar e julgar ações envolvendo o direito à saúde ${ }^{19}$.

O que notadamente se percebe é que houve avanço na área e um significativo enfrentamento da questão por parte do Judiciário, com a edição de portarias e normas pelo Conselho Nacional de Justiça (CNJ) no sentido de facilitar o diálogo entre os poderes Executivo e Judiciário, tratando cada caso de forma multidisciplinar e científica e integralizando os serviços de forma a propiciar ao paciente um empoderamento de sua ação e a efetivação de seus direitos.

Por outro ângulo, significa um ponto de tensão entre o Poder Judiciário e os elaboradores e executores da política pública no Brasil, que passam a receber um número cada vez maior de ordens judiciais, garantidoras das mais diversas prestações que representam gastos públicos não previstos nos orçamentos e desorganizam as políticas públicas vigentes ${ }^{20}$.

\section{Poder Judiciário no Maranhão: direito à saúde}

Com foco no âmbito do Poder Judiciário maranhense, realizou-se pesquisa jurisprudencial relativa aos casos sentenciados cujo tema debatido nos autos tenha sido pertinente à discussão do direito à saúde. Constatou-se, na pesquisa do repositório jurisprudencial do Tribunal de Justiça do Maranhão (TJ/MA), que, até o ano 2000, existiam julgados posicionando-se pela impossibilidade de o Judiciário intervir no controle de políticas públicas, seja pelo princípio da separação e harmonia dos poderes, seja pelo respeito à competência dos governantes para definir suas prioridades (poder discricionário), seja pelo argumento da limitação das disponibilidades orçamentárias e financeiras (reserva do possível).

A partir de 2001, é possível encontrar na jurisprudência do TJ/MA diversos julgados consolidando uma posição favorável ao controle de políticas públicas pelo Judiciário para garantia e efetivação de direitos fundamentais sociais à saúde.

\footnotetext{
${ }^{19}$ RAMOS, Edith Maria Barbosa; DINIZ, Isadora Moraes; MADUREIRA, Amanda Silva. O Conselho Nacional de Justiça: o Fórum da Saúde e o excesso de judicialização. Cad. Ibero-Amer. Dir. Sanit., Brasília, v. 4, n. 4, p. 86, out./dez. 2015. Disponível em: https://www.cadernos.prodisa.fiocruz.br/index.php/cadernos/article/ download/224/374. http://dx.doi.org/10.17566/ciads.v4i4.224.

${ }^{20}$ BLIACHERIENE, Ana Carla; SANTOS, José Sebastião dos; RUBIM, Thiago Freitas. op. cit., p. 76.
} 
A discricionariedade de prioridades exercida no campo do direito à saúde deve sempre visar à manutenção imediata da vida em primeiro lugar, e não ensejar situações ilegais, já que o respeito ao ordenamento jurídico é dever fundamental de qualquer esfera de governo.

Nos julgamentos de ações relativas à saúde, o Judiciário maranhense não teve por objetivo estabelecer prioridades na atuação da administração pública, em suposta substituição ao Poder Executivo estadual. Ocorre que a lei acoberta a discricionariedade desde que direitos fundamentais e indisponíveis, como é o direito à saúde, estejam devidamente amparados pela atuação do Estado.

Com base nos entendimentos do TJ/MA e do Supremo Tribunal Federal (STF), pode-se afirmar que, apesar de passados 10 anos desde a mudança de entendimento quanto ao direito à saúde pelo STF, permanece incólume o posicionamento do TJ/MA, principalmente em razão da importância da garantia de acesso a leito de UTI para manutenção da vida. Sendo assim, são vergastados argumentos que contrariem o artigo $196 \mathrm{da} \mathrm{CF} / 88$ e o direito fundamental à saúde, fortalecendo as decisões quanto ao direito à vida.

Dessa forma, o cidadão procura o Judiciário para que este intervenha quando seus direitos lhe foram usurpados e, agindo dessa maneira, o Poder Judiciário estará cumprindo seu papel de guardião da Constituição.

\section{Unidade de Terapia Intensiva: panorama nacional e estadual}

Diante da grande necessidade e importância da UTI dentro das unidades hospitalares, o Ministério da Saúde (MS) previu parâmetros de cobertura assistencial no âmbito do SUS por meio da Portaria GM n. 1.101/2002, posteriormente revogada pela Portaria n. 1.631/2015, atualmente em vigor, que atribui a responsabilidade pela revisão desses parâmetros:

$\$ 1^{\circ}$. Os Estados e Municípios podem promover a sua alteração, realizando os ajustes necessários para adequação à realidade epidemiológica, demográfica, patamares de oferta e ao estágio de estruturação da Rede de Atenção à Saúde existente em seus territórios.

Destaca-se que algumas denúncias feitas no ano de 2004 por pacientes ao Ministério Público Estadual (MPE) em São Luís relativas a leitos de UTI resultaram no ajuizamento pelo MPE de uma ação civil pública. Em 2017, o processo estava em grau de recurso (quando os réus recorrem da decisão).

Em 2012, o Ministério Público Federal (MPF) também ajuizou ação civil pública, com pedido de antecipação de tutela, contra o município de São Luís e contra a União. Essa ação teve como objetivo garantir aos usuários do SUS na capital 
maranhense assistência de urgência e emergência eficiente e igualitária - pois não é razoável aceitar que uma maca de ambulância se transforme em leito no corredor de um hospital e que este não receba nenhum centavo do MS nem do estado pelo atendimento prestado, o que ocorre rotineiramente em São Luís.

Dados de pesquisa realizada em 2016 pelo Conselho Federal de Medicina $(\mathrm{CFM})^{21}$ revelam que a oferta de leitos de UTI em estabelecimentos públicos ou conveniados ao SUS estão disponíveis em somente 505 dos 5.570 municípios brasileiros, de acordo com o Cadastro Nacional de Estabelecimentos de Saúde (CNES). Em 19 unidades da federação, o índice de UTI por habitante na rede pública é inferior ao preconizado pelo próprio Ministério da Saúde - todos os estados das regiões Norte (exceto Rondônia), Nordeste (exceto Pernambuco e Sergipe) e Centro-Oeste, além do Rio de Janeiro e Santa Catarina. No Acre, em Roraima, no Amapá e no Maranhão, o índice permanece abaixo do ideal, mesmo se considerados os leitos privados disponíveis nesses estados.

Se consideradas as unidades públicas e privadas, a quantidade de leitos de UTI representam, atualmente, 9,3\% dos leitos de internação existentes no Brasil - em outras palavras, há 1,86 leito para cada grupo de 10 mil habitantes. Proporcionalmente, no entanto, o SUS conta com 0,95 leito de UTI para cada grupo de $10 \mathrm{mil}$ habitantes, enquanto a rede "não SUS" tem 4,5 leitos para cada 10 mil beneficiários de planos de saúde - quase cinco vezes a oferta da rede pública ${ }^{22}$.

Uma das estratégias para o enfrentamento do elevado número de processos judiciais em São Luís e a desjudicialização da saúde foi a criação, em 2015, do Portal de Atenção à Saúde (PAS) pela Secretaria Estadual de Saúde (SES) do Maranhão, que potencializou o intercâmbio de informações e o atendimento dos pacientes. Contudo, as principais demandas da judicialização depois do PAS continuaram sendo o fornecimento de medicamentos e a obtenção de leitos para internação, assim como ocorria antes ${ }^{23}$.

Diante desse panorama, pode-se trazer à baila o pensamento de Ana Luiza Chieffi e Rita Barata, que traduz:

No campo específico da política de saúde, a judicialização tem se traduzido como a garantia de acesso a bens e serviços por intermédio do recurso a ações judiciais. Com o aumento exponencial das ações e a impossibilidade de previsão orçamentária

\footnotetext{
${ }^{21} 5065$ MUNICÍPIOS brasileiros não possuem leitos de UTI, aponta estudo do CFM. Estudo inédito do CFM revela que leitos de Unidades de Terapia Intensiva no Brasil são insuficientes e estão mal distribuídos. Conselho Federal de Medicina - CFM, 16 maio 2016. Disponível em: https://portal.cfm.org.br/index.php?option=com_ content\&view=article\&id=26167:2016-05-16-12-15-52\&catid=3. Acesso em: 03 fev. 2017.

${ }^{22}$ Id. Ibid.

${ }^{23}$ NUNES, Heraldo Elias Nogueira. A prática da mediação e a (des) judicialização da saúde no Maranhão. 2016. Dissertação (Mestrado) - Universidade Ceuma, São Luís-MA, 2016.
} 
dos gastos por elas acarretados, os gestores do sistema de saúde, nos âmbitos municipal, estadual e federal, tentam resolver de diversas maneiras os impasses criados $^{24}$.

Faz-se necessária a soma de esforços no sentido de contribuir para o entendimento da judicialização da saúde, por parte tanto dos juristas, legisladores e doutrinadores, quanto dos pesquisadores, profissionais e gestores da saúde, por meio de estudos, discussões e debates de ideias que se transformem em ações e estratégias para agilizar a resolução de conflitos na saúde, tornando a resposta mais célere e equilibrada dentro da realidade vivenciada em sociedade.

\section{Resultados e análise dos dados}

Foram selecionados 25 processos em que houve pedido de leito de UTI adulto, no período de janeiro de 2009 a fevereiro de 2016. Nesses processos, verificou-se, entre os elementos caracterizadores, o perfil daqueles que demandaram por leitos de UTI: 14 deles (56\%) eram do gênero masculino, enquanto 11 (44\%) eram do feminino. Débora Diniz ${ }^{25}$ obteve dados semelhantes sobre variáveis de processos judiciais no Distrito Federal (DF), em que 197 (51\%) foram do gênero masculino. Isso reforça informações do Ministério da Saúde de que tal fato decorre de a população masculina não cuidar de sua saúde, ao contrário das mulheres. Estudos comparativos entre homens e mulheres apontam que os homens adoecem mais gravemente que as mulheres, pois não buscam atendimento preventivamente ${ }^{26}$.

Em relação à demanda por faixa etária (anos), concentrou-se o maior número de solicitações de UTI entre 80 a 99 anos (11 processos, 44\%), seguido de oito (32\%) entre 60 a 79 anos, e um (4\%) acima de 100 anos. Abaixo de 60 anos, foram somente cinco solicitações $(20 \%)$. Foram encontrados por Débora Diniz ${ }^{27}$ no DF dados que corroboram o perfil em São Luís: a maioria foi de idosos entre 70 a 79 anos de idade. Esse dado demonstra a importância dos programas do Ministério da Saúde em relação ao idoso e confirma os estudos realizados no país sobre o perfil de morbidade populacional e o padrão de utilização de serviços de saúde em localidades urbanas pela população idosa.

Em relação à representação jurídica do autor da ação, o tipo de advocacia que teve maior representatividade foram os escritórios particulares, em 15 processos

\footnotetext{
${ }^{24}$ CHIEFFI, Ana Luiza; BARATA, Rita Barradas. Judicialização da política pública de assistência farmacêutica e eqüidade. Cad. Saúde Pública, Rio de Janeiro, v. 25, n. 8, p. 1839-1849, ago. 2009. Disponível em: http://www.scielo.br/scielo.php?script=sci_arttext\&pid=S0102-311X2009000800020\&lng=en\&nrm=i so. http://dx.doi.org/10.1590/S0102-311X2009000800020.

${ }^{25}$ DINIZ, Debora; MACHADO, Teresa Robichez de Carvalho; PENALVA, Janaina. op. cit.

${ }^{26}$ MINISTÉRIO DA SAÚDE - MS. Política Nacional de Atenção Integral à Saúde do Homem: Princípios e Diretrizes. Brasília, DF: Ministério da Saúde, 2010.

${ }^{27}$ DINIZ, Debora; MACHADO, Teresa Robichez de Carvalho; PENALVA, Janaina. op. cit.
} 
(60\%), enquanto a Defensoria Pública do Estado (DPE) atuou 10 (40\%) dos processos analisados. Luiz Carlos Romero ${ }^{28}$, em sua pesquisa realizada no TJ/DF, obteve majoritariamente advogados particulares (95\%), enquanto o Ministério Público atuou em $2,3 \%$ das ações julgadas. Se a grande maioria das ações é proposta por particulares por meio de advogados, isso pressupõe que os autores têm condições socioeconômicas suficientemente elevadas para custear uma causa (além de conexões sociais, grau de escolaridade e discernimento suficientes para conhecer a possibilidade de recurso judicial e decidir-se por usá-lo). Existe um custo fixo inicial para causas jurídicas com advogados particulares que não é acessível aos mais pobres ${ }^{29}$, Contudo, a falta de informação quanto à renda do paciente nos processos selecionados não permite analisar nem concluir a qual classe social pertencem os autores/pacientes.

Em todos os 25 processos selecionados, o autor da ação ingressou de forma individual (100\%), ou seja, não foram encontrados processos coletivos. Os autores das ações têm buscado individualmente o auxílio do sistema judiciário por não encontrarem uma forma rápida e eficaz para o atendimento de sua necessidade por meio administrativo. Assim como os autores/pacientes das 87 ações pesquisadas por Idelisa Cabral e Laura Ferreira de Rezende ${ }^{30}$ ingressaram individualmente, dados também encontrados por Silvia Badim Marques e Sueli Gandolf Dallari ${ }^{31}$ no Estado de São Paulo mostram autores individuais como a maioria dos titulares das ações. Com essas demandas judiciais, pretende-se garantir direitos sociais que são essencialmente coletivos. Entretanto, como a atuação do Poder Judiciário ocorre no âmbito individual, isto é, de forma individualizada, demonstra tratamento diferenciado, privilegiando esses pacientes, o que é incompatível com a ideia de igualdade proposta pelo SUS ${ }^{32}$. Ninguém pode, portanto, ser individualmente responsável por sua saúde ${ }^{33}$.

Quanto à origem do Atendimento de Saúde, constatou-se que a rede pública foi prestadora desse serviço em 16 (64\%) dos processos analisados, enquanto nove (36\%) foram atendidos na rede privada de saúde.

\footnotetext{
${ }^{28}$ ROMERO, Luiz Carlos. A jurisprudência do tribunal de justiça do distrito federal em ações de medicamentos. Revista de Direito Sanitário, São Paulo v. 11, n. 2 p. 19 jul./out. 2010. Disponível em: http://www.revistas. usp.br/rdisan/article/view/13207/15018. https://doi.org/10.11606/issn.2316-9044.v11i2p11-59.

${ }^{29}$ BLIACHERIENE, Ana Carla; SANTOS, José Sebastião dos; RUBIM, Thiago Freitas. op. cit., p. 76.

${ }^{30}$ CABRAL, Ildelisa; DE REZENDE, Laura Ferreira. Análise das Ações Judiciais Individuais para Fornecimento de Medicamentos em São João da Boa Vista. Revista de Direito Sanitário, v. 16, n. 1, p. 59-77, 2015. Disponivel em: http://www.revistas.usp.br/rdisan/article/view/100017/98606. https://doi.org/10.11606/ issn.2316-9044.v16i1p59-77.

${ }^{31}$ MARQUES, Silvia Badim; DALLARI, Sueli Gandolfi. Garantia do direito social à assistência farmacêutica no Estado de São Paulo. Rev. Saúde Pública, v. 41, n. 1, p. 101-107, 2007. Disponível em: http://www.scielo. br/pdf/rsp/v41n1/15.pdf. http://dx.doi.org/10.1590/S0034-89102007000100014.

${ }^{32} \mathrm{CHIEFFI}$, Ana Luiza; BARATA, Rita Barradas. op. cit.

${ }^{33}$ DALLARI, Sueli Gandofi. A construção do direito à saúde no Brasil. Revista de Direito Sanitário, São Paulo, v. 9, n. 3 p. 9-34, nov. 2008/fev. 2009. Disponível em: http://www.revistas.usp.br/rdisan/article/ view/13128/14932. https://doi.org/10.11606/issn.2316-9044.v9i3p9-34.
} 
A mesma realidade foi encontrada por Débora Diniz ${ }^{34}$, com $85 \%$ dos demandantes encaminhados com receita médica oriunda de serviços públicos de saúde. Resultados similares foram obtidos por Fabíola Sulpino Vieira e Paola Zuchi ${ }^{35}$, com os serviços do SUS originando 59\% das prescrições. Percebe-se que, apesar das dificuldades no atendimento, da diversidade de problemas de saúde e do pouco recurso disponibilizado ao SUS, os pacientes buscam atendimento e assistência à saúde em Unidades de Pronto Atendimento (UPA), como é o caso da maioria dos autores de ações judiciais com pedido de UTI em São Luís.

É pertinente acentuar que o Estado do Maranhão foi o que mais frequentemente figurou como réu, em 23 (92\%) dos processos analisados. Havia mais de um réu em 14 ações, sendo que o Estado do Maranhão e o município de São Luís figuraram simultaneamente como réus em 10 processos. Contudo, o município aparece como único réu somente em dois (8\%) processos. Corroborando esta pesquisa, dados de José Gilberto Pereira e Vera Lúcia Edias Pepe ${ }^{36}$ mostram que a Secretaria de Estado da Saúde do Paraná figurou como réu na maioria dos processos judiciais. E, segundo dados de Luiz Carlos Romero ${ }^{37}$, em mais de $90 \%$ das ações judiciais o réu é a Secretaria de Estado da Saúde do DF. A possível reposta para o estado ser réu em grande parte dos processos judiciais é o fato de que possui maior número de leitos de UTI em São Luís/MA.

Analisando a relação do tempo de duração da ação/processo, constatou-se que $12(48 \%)$ perduraram mais de três anos, oito (32\%) levaram de dois e três anos e cinco processos (20\%) tramitaram por menos de dois anos (período em que foram representados por escritórios particulares). Importante destacar que nem sempre a rapidez da determinação judicial significou celeridade processual, pois, em alguns casos/processos, o paciente foi a óbito pouco depois da entrada da petição. Por exemplo, existiram casos de óbito no dia seguinte e uma semana após a data de entrada; nesses casos, houve a extinção do processo, o que ocorreu em seis (24\%) das ações analisadas.

Para análise dos critérios nas decisões das varas da fazenda pública em São Luís, foi necessário destacar os principais argumentos que o juiz utilizou para atender ao pedido de UTI, sendo que, em muitos dos processos, o representante jurídico utilizou várias leis e princípios que resguardam o direito do paciente. Assim sendo,

\footnotetext{
${ }^{34}$ DINIZ, Debora; MACHADO, Teresa Robichez de Carvalho; PENALVA, Janaina. op. cit.

${ }^{35}$ VIEIRA, Fabiola Sulpino; ZUCCHI, Paola. Distorções causadas pelas ações judiciais à política de medicamentos no Brasil. Distorções causadas pelas ações judiciais à política de medicamentos no Brasil. Rev. Saúde Pública, v. 41, n. 2, p. 214-222, 2007. Disponível em: http://www.scielo.br/pdf/rsp/ v41n2/5587.pdf. http://dx.doi.org/10.1590/S0034-89102007000200007.

${ }^{36}$ PEREIRA, José Gilberto; PEPE, Vera Lúcia Edais. Acesso a medicamentos por via judicial no Paraná: aplicação de um modelo metodológico para análise e monitoramento das demandas judiciais. Revista de Direito Sanitário, v. 15, n. 2, p. 30-45, 2015. Disponível em: http://www.revistas.usp.br/rdisan/article/ view/88355/91231. https://doi.org/10.11606/issn.2316-9044.v15i2p30-45.

${ }^{37}$ ROMERO, Luiz Carlos. op. cit.
} 
o juiz geralmente fez uso da mesma linha argumentativa do representante jurídico. Vejamos o que segue em trecho de uma decisão judicial:

[...] Assegurar o direito à saúde não é ingerência indevida do Poder Judiciário nos atos administrativos do Estado, de onde o juiz não estará violando o princípio da Separação dos Poderes, mas exercendo a função jurisdicional que lhe é atribuída, a qual dentre outros ideais consagra que: a lei não excluirá da apreciação do Poder Judiciário lesão ou ameaça a direito XXXV, Art. $5^{\circ}$ $\mathrm{CF} / 88$. (Processo 08)

Em relação ao cumprimento das decisões, em todos os processos o juiz foi favorável à concessão de leito de UTI adulto aos solicitantes. Todavia, alguns pacientes foram a óbito devido à gravidade de seu estado de saúde e outros, devido ao lapso temporal entre a decisão do juiz e o cumprimento na medida de urgência.

A seguir, algumas situações são descritas para melhor compreensão do percurso vivenciado pelo paciente e seus familiares até o acesso ou não ao leito de UTI. Com base nos fatos narrados e no desfecho final do processo:

Paciente necessitando de cuidados intensivos estava internado em uma enfermaria, porque neste hospital não havia vaga disponível na UTI e a Central de Regulação do Estado e Município não tinham [sic] previsão de leito. Neste ínterim, sua família percorria desesperada vários locais públicos, em busca de atendimento jurídico, não conseguindo, pagou advogado e, após 07 dias nesta luta, o paciente foi a óbito, sem ter acesso ao leito de UTI. (Processo 10).

A paciente, nesse momento, está na "fila de espera" da Central de Regulação de leitos do Estado do Maranhão, por absoluta falta de leitos de UTI nos hospitais públicos e privados de São Luís (Relato do Oficial de Justiça do Fórum após percorrer todos os hospitais da capital) (Processo 03).

Transparece uma fragilidade na rede de assistência à saúde pública, dificultando o acesso a um serviço que gira em torno da resolução imediata das situações urgentes e emergenciais da maioria dos pacientes graves. Além disso, a dificuldade de acesso à Justiça não é diferente da dificuldade de acesso à saúde: ambos os serviços têm demanda excessiva, e muitas cidades não dispõem de recurso financeiro ou de pessoal para satisfazer os anseios da população.

Assim, demonstra-se, por meio das decisões judiciais locais relacionadas à saúde, que, muito embora tais demandas possam ser concedidas, pode ocorrer a não efetivação do acesso pela insuficiência de leitos e/ou pela demora no cumprimento das determinações judiciais, evidenciando que há necessidade de aprimoramento ou desenvolvimento 
de um sistema que diminua o tempo-resposta, tornando mais célere o atendimento, principalmente quando se tratar de pacientes graves com necessidade de UTI.

Uma proposta para resolução de conflitos dentro do sistema de saúde pode ser a mediação, muito utilizada na Espanha não só na saúde, mais em todas as áreas, como educação, empresas, contratos, dentre outras. No entanto, nas situações que envolvam a saúde, a mediação sanitária torna-se mais adequada, pois é uma opção que proporciona às partes um diálogo com a ajuda de um terceiro (facilitador), que não dá conselhos nem toma decisões, mas cria uma atmosfera propícia à identificação das necessidades de ambas as partes na tentativa de chegar a um consenso e resolver o(s) problema(s) que envolve $(\mathrm{m})$ diferentes percepções, opiniões, saberes, culturas e crenças, dada a urgência e relevância da situação em questão - a vida.

A pesquisadora Maria Célia Delduque, em seu artigo sobre Mediação Sanitária como alternativa, conceitua Mediação como “[...] método pacífico de gestão de conflitos, que pretende evitar a abertura de processos judiciais de caráter contencioso e pôr fim àqueles iniciados ou reduzir o seu alcance" ${ }^{38}$.

Ainda, segundo Delduque:

Mediação Sanitária é um modelo alternativo de resolução de conflitos na área da saúde. As relações em saúde transcendem a ótica bilateral do médico com o paciente, para envolver muitos outros atores presentes em um sistema de saúde, advindo, daí conflitos de toda a ordem, internos e externos ao sistema, criando condições para a judicialização. Conflitos internos (como os assistenciais, organizativos e conflitos entre profissionais) geram desgastes e judicialização, como também fazem os conflitos gerados fora do sistema, mas com reflexos diretos dentro dele, assim como os conflitos sociais e conflitos legais igualmente geram a judicialização ${ }^{39}$.

Nesse diapasão, Gilmar Assis afirma que:

[...] a Mediação trabalha na perspectiva da tríade Direito, Saúde e Cidadania, por acreditar que é possível a convergência do diálogo entre eles (Sistema de Saúde x Sistema Judicial). Parte do pressuposto de que a atuação solitária de quaisquer desses atores, que integram esse fundamental Sistema de Saúde, não contribui para a necessária efetivação do Direito à Saúde. Nesse sentido, não é razoável a atuação judicial divorciada dos pressupostos técnicos, assim como não é possível que a técnica esteja em dissintonia com a social ${ }^{40}$.

\footnotetext{
${ }^{38}$ DELDUQUE, Maria Célia. A mediação sanitária como um novo paradigma alternativo à judicialização das políticas de saúde no Brasil. Brasília-DF: CONASS, 2015. p. 4.

${ }^{39}$ Id., loc. cit.

${ }^{40}$ ASSIS, Gilmar. Mediação sanitária: direito, saúde e cidadania. Brasília, DF: CONASS, 2015. Disponível em: https://www.mpma.mp.br/index.php/centros-deapoio/saude/assistance-de-medica/mediacao-sanitaria. Acesso em: 28 nov. 2017.
} 
A atual conjuntura socioeconômica e política do Brasil exige novas formas de proceder na resolução de conflitos, especialmente no contexto da rede pública de saúde, adequando o instituto da mediação com o sistema. de gestão para fornecer uma alternativa à cultura de judicialização da saúde - que cresce exponencialmente, com temas mais difíceis e até inéditos, tornando a decisão judicial um acontecimento midiático em alguns casos, por exemplo, terapias experimentais de patologias pouco conhecidas ou sem pesquisa conclusiva no momento.

Sendo assim, a mediação sanitária torna-se cada vez mais atual e necessária na resolução de conflitos, principalmente em questões relacionadas a pacientes graves, que precisam de resposta rápida e ações imediatas para decidir seus destinos. Assim como, exercício da cidadania e salvaguarda de seus direitos fundamentais, como o direito à saúde, à vida e à morte com dignidade, assistência humanizada $\mathrm{e}$ qualificada.

Portanto, a garantia de acesso universal e igualitário às ações e aos serviços de saúde é tão importante quanto o atendimento singular do indivíduo. Porém, essa garantia depende, entre outros fatores, de aplicação adequada dos recursos às políticas de saúde. Assim, a universalidade do acesso ao SUS é para todo aquele que, de alguma maneira, necessite de seus serviços.

\section{Considerações finais}

Os princípios que delineiam o SUS no Brasil, quais sejam, a universalidade, a integralidade e a equidade, mostram-se imperativos na prática dos serviços de saúde. Embora as vicissitudes de ordem econômica e social no país apresentem representações distintas, a depender da gestão e dos determinantes sociais que consubstanciam a adoção de políticas específicas em cada região do país, esses princípios não devem resvalar a um denominador da ordem da reserva do possível.

Destarte, o cidadão que necessita de algum cuidado especial termina provocando o Poder Judiciário para garantir o direito à saúde, que muitas vezes está ligado a um pedido de autorização para realizar uma cirurgia, obter leito de UTI ou algum tratamento através de medicamentos de uso contínuo ou experimental. Isso gerou o que está intitulado hoje como judicialização da saúde.

O Judiciário maranhense encontrava-se em uma trincheira ideológica até meados do ano 2000, quando, após alguns julgados e com base na jurisprudência superior, mudou suas interpretações e partiu para a concessão dos pedidos de leitos e insumos com base na valoração do direito à vida, em detrimento da argumentação do Estado em relação ao orçamento público, assim como entendimento majoritário do STF. Todavia, o Judiciário do Maranhão carece de mais recursos técnicos para atender às resoluções e recomendações do CNJ, principalmente a 
criação de um sistema que armazene informações sobre os processos, como um banco de dados.

Dos processos judiciais analisados nesta pesquisa, o maior número foi demandado individualmente pelo gênero masculino, com representação por advogado particular; prevaleceram idosos, na faixa etária entre 80 e 99 anos de idade. Prevaleceu o tempo de tramitação de mais de três anos e, em algumas ações, pacientes foram a óbito pouco tempo após a abertura dos processos, sendo extintos sem resolução do pedido, ou seja, sem efetivar o direito de acesso ao leito de UTI.

A maioria dos juízes utilizou a Constituição Federal de 1988, notadamente o direito à saúde, como critério para a tomada de decisão. Cabe ressaltar que, no cumprimento das decisões, um maior número de pacientes obteve acesso à UTI, apesar da dificuldade de encontrar leitos disponíveis nas redes pública e privada de saúde na cidade de São Luís.

Importante destacar que estão aumentando as solicitações no Poder Judiciário por leitos de UTI em hospitais particulares, diante do déficit nos hospitais da rede pública em São Luís e no interior do Maranhão. Portanto, infere-se que há influência da judicialização nos fluxos de regulação dos leitos, o que pode ser um indicador do cumprimento do direito fundamental à saúde quando meios e insumos não estão garantidos pelo SUS. Entretanto, é preciso estar atento para manobras político-capitalísticas de indução de demandas e recursos do SUS para a rede privada, postergando a qualificação da rede pública para cumprir suas missões na recuperação da saúde de pacientes graves.

A SES/MA criou o Portal de Atenção à Saúde (PAS) para diminuir as demandas jurídicas, contudo não criou um canal de diálogo, como a Mediação Sanitária, que tenha essa função maior, o que poderia contribuir não só para a diminuição da judicialização - vista por muitos gestores públicos como um único problema a ser resolvido -, como também para o planejamento coletivo da implementação das políticas públicas em ações e serviços de saúde.

Diante da premente necessidade de diálogo entre os poderes Executivo e Judiciário no intuito de tornar mais célere o atendimento das demandas, bem como de haver interação de saberes de todos os envolvidos para a diminuição das situações de injustiça social e o aumento da equidade nas condições de saúde, cresce a importância do instituto da Mediação Sanitária. Esta seria uma alternativa mais rápida e eficaz, pois, na mesa de mediação, há o empoderamento do paciente e a possibilidade de diálogo entre os sistemas de saúde, a administração pública e o Judiciário maranhense. O resultado seria o fortalecimento do núcleo essencial-fundamental, ou seja, os direitos sociais fundamentais que constituem a "essência" da Constituição em nosso Estado Democrático de Direito e o cumprimento da garantia constitucional do direito à saúde para todos. 


\section{Referências}

5065 MUNICÍPIOS brasileiros não possuem leitos de UTI, aponta estudo do CFM. Estudo inédito do CFM revela que leitos de Unidades de Terapia Intensiva no Brasil são insuficientes e estão mal distribuídos. Conselho Federal de Medicina - CFM, 16 maio 2016. Disponível em: https://portal.cfm.org.br/index.php?option $=$ com_content\&view $=$ article\&id=26167:2016-05 -16-12-15-52\&catid=3. Acesso em: 03 fev. 2017.

AITH, Fernando Mussa Abujamra. Curso de direito sanitário: a proteção do direito à saúde no Brasil. São Paulo: Quartier Latin, 2007.

AITH, Fernando Mussa Abujamra; BUJDOSO, Yasmin; NASCIMENTO, Paulo Roberto do; DALLARI, Sueli Gandolfi. Os princípios da universalidade e integralidade do SUS sob a perspectiva da política de doenças raras e da incorporação tecnológica. Revista de Direito Sanitário, São Paulo, v.15, n.1, p. 10-39, mar./jun. 2014. Disponível em: http://www.revistas. usp.br/rdisan/article/viewFile/82804/85759. Acesso em: 10 abr. 2018. https://doi.org/10.11606/ issn.2316-9044.v15ilp10-39.

ASSIS, Gilmar. Mediação sanitária: direito, saúde e cidadania. Brasília, DF: CONASS, 2015. Disponível em: https://www.mpma.mp.br/index.php/centros-deapoio/saude/ assistance-de-medica/mediacao-sanitaria. Acesso em: 28 nov. 2017.

BARROSO, Luís Roberto. Judicialização, ativismo judicial e legitimidade democrática. Anuário Iberoamericano de Justiça Constitucional, n. 13, p. 17-32, 2009. Disponível em: https://www.e-publicacoes.uerj.br/index.php/synthesis/article/download/7433/5388. Acesso em: 21 dez. 2016.

BLIACHERIENE, Ana Carla; SANTOS, José Sebastião dos; RUBIM, Thiago Freitas. Delimitação do sentido normativo dos princípios doutrinários do direito à saúde como parâmetro mitigador da judicialização das políticas públicas de saúde. Revista Eletrônica Jurídica, v. 3, n. 2, 2016. Disponível em: http://www.periodicosibepes.org.br/index.php/redir/ article/view/2402. Acesso em: 02 abr. 2018.

CABRAL, Ildelisa; DE REZENDE, Laura Ferreira. Análise das Ações Judiciais Individuais para Fornecimento de Medicamentos em São João da Boa Vista. Revista de Direito Sanitário, v. 16, n. 1, p. 59-77, 2015. Disponível em: http://www.revistas.usp.br/rdisan/article/ view/100017/98606. https://doi.org/10.11606/issn.2316-9044.v16i1p59-77.

CALLIARI, Gabriela; TEIXEIRA, Alessandra Vanessa. A judicialização da saúde e a má distribuição de recursos para medicamentos de baixa escala e/ou alto custo. Revista Eletrônica Direito e Política, v. 12, n. 1, p. 202-220, 2017. Disponível em: https://siaiap32.univali.br/seer/ index.php/rdp/article/view/10407/0. Acesso em: 13 mar. 2018.

CHIEFFI, Ana Luiza; BARATA, Rita Barradas. Judicialização da política pública de assistência farmacêutica e eqüidade. Cad. Saúde Pública, Rio de Janeiro, v. 25, n. 8, p. 1839-1849, ago. 2009. Disponível em: http://www.scielo.br/scielo.php?script=sci_arttext\&pid=S0102-311X 2009000800020\&lng=en\&nrm=iso. http://dx.doi.org/10.1590/S0102-311X2009000800020. 
Investigação de UTI sob a ótica da judicialização da saúde

DALlARI, Sueli Gandofi. A Construção do Direito à Saúde no Brasil. Revista de Direito Sanitário, São Paulo, v. 9, n. 3 p. 9-34, nov. 2008/fev. 2009. Disponível em: http://www.revistas. usp.br/rdisan/article/view/13128/14932. https://doi.org/10.11606/issn.2316-9044.v9i3p9-34.

DALLARI, Sueli Gandolfi. Aspectos particulares da chamada judicialização da saúde. Revista de Direito Sanitário, São Paulo, v. 14, n. 1, p. 77-81, mar./jun. 2013. Disponível em: http://www.revistas. usp.br/rdisan/article/view/56624/59641. https://doi.org/10.11606/issn.2316-9044.v14i1p77-81.

DELDUQUE, Maria Célia. A mediação sanitária como um novo paradigma alternativo à judicialização das políticas de saúde no Brasil. Brasília-DF: CONASS, 2015. 8 p.

DINIZ, Debora; MACHADO, Teresa Robichez de Carvalho; PENALVA, Janaina. A judicialização da saúde no Distrito Federal, Brasil. Ciênc. saúde coletiva, Rio de Janeiro, v. 19, n. 2, p. 591-598, fev. 2014. Disponível em: http://www.scielo.br/scielo.php?script=sci_ar ttext\&pid=S1413-81232014000200591\&lng=en\&nrm=iso. Acesso em: 03 jan. 2017. http:// dx.doi.org/10.1590/1413-81232014192.23072012. Acesso em: 3 jan. 2017.

FABRINI, Fábio; FORMENTI, Lígia; FELIX, Paula. Despesa “judicial” no Ministério da Saúde avança 1.300\% em 7 anos. Revista Exame, São Paulo, p. 1-5, ago. 2017. Disponível em: http:// exame.abril.com.br/brasil/despesa-judicial-no-ministerio-da-saude-avanca-1-300-em-7anos/. Acesso em: 23 out. 2017.

GOMES, Vanessa Santana; AMADOR, Tania Alves. Estudos publicados em periódicos indexados sobre decisões judiciais para acesso a medicamentos no Brasil: uma revisão sistemática. Cad. Saúde Pública, Rio de Janeiro, v. 31, n. 3, p. 451-462, mar. 2015. Disponível em: http://www.scielo.br/scielo.php?script=sci_arttext\&pid=S0102-311X2015000300451\&l ng=en\&nrm=iso. http://dx.doi.org/10.1590/0102-311x00219113.

MACHADO, Teresa Robichez. Judicialização da saúde e contribuições da teoria de justiça de Norman Daniels. Revista de Direito Sanitário, São Paulo, v. 16, n. 2, p. 52-76, jul./out. 2015. Disponível em: http://www.revistas.usp.br/rdisan/article/view/106891/105511. https://doi. org/10.11606/issn.2316-9044.v16i2p52-76.

MARQUES, Silvia Badim; DALLARI, Sueli Gandolfi. Garantia do direito social à assistência farmacêutica no Estado de São Paulo. Rev. Saúde Pública, v. 41, n. 1, p. 101-107, 2007. Disponível em: http://www.scielo.br/pdf/rsp/v41n1/15.pdf. http://dx.doi.org/10.1590/ S0034-89102007000100014.

MINISTÉRIO DA SAÚDE - MS. Política Nacional de Atenção Integral à Saúde do Homem: Princípios e Diretrizes. Brasília, DF: Ministério da Saúde, 2010.

NUNES, Heraldo Elias Nogueira. A prática da mediação e a (des) judicialização da saúde no Maranhão. 2016. Dissertação (Mestrado) - Universidade Ceuma, São Luís-MA, 2016.

PEREIRA, José Gilberto; PEPE, Vera Lúcia Edais. Acesso a medicamentos por via judicial no Paraná: aplicação de um modelo metodológico para análise e monitoramento das demandas judiciais. Revista de Direito Sanitário, v. 15, n. 2, p. 30-45, 2015. Disponível em: http://www.revistas. usp.br/rdisan/article/view/88355/91231. https://doi.org/10.11606/issn.2316-9044.v15i2p30-45. 
RAMOS, Edith Maria Barbosa; DINIZ, Isadora Moraes; MADUREIRA, Amanda Silva. O Conselho Nacional de Justiça: o Fórum da Saúde e o excesso de judicialização. Cad. Ibero-Amer. Dir. Sanit., Brasília, v. 4, n. 4, p. 81-89, out./dez. 2015. Disponível em: https:// www.cadernos.prodisa.fiocruz.br/index.php/cadernos/article/download/224/374. http:// dx.doi.org/10.17566/ciads.v4i4.224.

ROMERO, Luiz Carlos. A jurisprudência do tribunal de justiça do distrito federal em ações de medicamentos. Revista de Direito Sanitário, São Paulo v. 11, n. 2 p. 11-59 jul./out. 2010. Disponível em: http://www.revistas.usp.br/rdisan/article/view/13207/15018. https://doi. org/10.11606/issn.2316-9044.v11i2p11-59.

TORRES, Izamara Damasceno Catanheide. Judicialização do acesso a medicamentos no Brasil: uma revisão sistemática. Salvador: [s.n.], 2013.

VIEIRA, Fabiola Sulpino; ZUCCHI, Paola. Distorções causadas pelas ações judiciais à política de medicamentos no Brasil. Distorções causadas pelas ações judiciais à política de medicamentos no Brasil. Rev. Saúde Pública, v. 41, n. 2, p. 214-222, 2007. Disponível em: http:// www.scielo.br/pdf/rsp/v41n2/5587.pdf. http://dx.doi.org/10.1590/S0034-89102007000200007.

WANG, Daniel Wei L.; VASCONCELOS, Natália Pires de; OLIVEIRA, Vanessa Elias de; TERRAZAS, Fernanda Vargas. Os impactos da judicialização da saúde no município de são paulo: gasto público e organização federativa. Rev. Adm. Pública, Rio de Janeiro, v. 48, n. 5, p. 1191-1206, out. 2014. Disponível em: http://www.scielo.br/pdf/rap/v48n5/06.pdf. http:// dx.doi.org/10.1590/0034-76121666.

YEPES, Rodrigo Uprimny. A judicialização da política na Colômbia: casos, potencialidades e riscos. Revista Internacional de Direitos Humanos, São Paulo, São Paulo, v. 6, n. 4, 2007.

YEPES, Rodrigo Uprimny. A judicialização da política na Colômbia: casos, potencialidades e riscos. Sur, rev. int. direitos human., São Paulo, v. 4, n. 6, p. 52-69, 2007. Disponível em: http://www.scielo.br/scielo.php?script=sci_arttext\&pid=S1806-64452007000100004\&lng=e n\&nrm=iso. http://dx.doi.org/10.1590/S1806-64452007000100004. 
Investigação de UTI sob a ótica da judicialização da saúde

Adriana do Lago Alves Costa - Mestrado em Gestão de Programas e Serviços de Saúde pela Universidade Ceuma; graduação em Direito pela Faculdade Santa Terezinha - CEST; graduação em Enfermagem pela Universidade Ceuma. São Luís/MA, Brasil. E-mail: adrilagosluis@gmail.com

Ana Maria Fernandes Pitta - Pós-Doutorado em Epidemiologia e Psiquiatria Social pelo Istituto de Recherche Mario Negri (Milão, Itália); pós-doutorado em Avaliação em Saúde Mental pela McGill University (Montreal, Canadá); pós-doutorado pelo Dèpartement de L'Administration et Santé da Université Montrèal (Montreal, Canadá); doutorado e mestrado em Medicina Preventiva/Saúde Mental pela Universidade de São Paulo (USP); graduação em Medicina pela Universidade Federal da Bahia. Professora adjunta da Universidade Católica de Salvador; professora colaboradora no Centro de Estudos e Pesquisas de Direito Sanitário (Cepedisa).São Luís/MA, Brasil. E-mail: ana.pitta@pro.ucsal.br

Edith Maria Barbosa Ramos - Doutorado em Políticas Públicas pela Universidade Federal do Maranhão (UFMA); mestrado em Direito pela Universidade Federal de Minas Gerais (UFMG); graduação em Direito pela Universidade Federal do Maranhão (UFMA). Professora da UFMA; coordenadora do Núcleo de Estudos em Direito Sanitário da UFMA; professora e pesquisadora da Universidade Ceuma. São Luís/MA, Brasil. E-mail: edithramosadv@yahoo.com.br 